\title{
A terceirização do controle: uma análise sobre a fiscalização do comércio ambulante, entre trabalho e gênero
}

Tarcísio Perdigão Araújo Filho'

Resumo: Este texto apresenta reflexões sobre como se constrói a fiscalização sobre o comércio ambulante, levando em conta o ponto de vista do trabalho dos funcionários terceirizados do poder público implicados diretamente na operacionalização do controle nas ruas de Belo Horizonte. Denominados genericamente como auxiliares de fiscalização, estes agentes realizam funções diversas de caráter operacional e subalterno, ainda que representem a base da rotinização deste tipo específico de controle social, sempre postos a interagir diretamente com os fiscalizados. Levando em conta que a fiscalização é uma construção social multi-dimensional, este estudo aposta em categorias emergentes da perspectiva cruzada entre trabalho e gênero, propiciadas, por sua vez, pela análise de trajetórias sociais destes sujeitos.

Palavras-chave: Terceirização; Gênero; Trabalho masculino; Comércio ambulante

The outsourcing of control: an analysis of the street vending inspection through gender and work perspectives

Abstract: This text presents thoughts on how the street vending control is produced taking into account the point of view of the outsourced employees directly

1 Programa de Pós-Graduação em Sociologia da Universidade Federal de São Carlos (UFSCar) - São Carlos - Brasil - tarcisioperdigao@gmail.com 
involved in the operationalization of street practices regulation in Belo Horizonte. Generally known as inspection assistants, these agents perform various subaltern functions, always in a position to interact with the street vendors. These outsorced agents represents the basis of the routinization of this specific type of social control. Considering that the State control is a multi-dimensional social construction, this study focuses on categories that emerges from the crossed perspective between work and gender, provided, in turn, by the the subjects trajectories analysis.

\section{Keywords: Outsourcing; Gender; Masculine work; Street vending}

\section{Introduç̃̃o}

Este texto tem o objetivo de apresentar algumas reflexões suscitadas pela análise de trajetórias dos auxiliares de fiscalização, trabalhadores terceirizados pela Prefeitura de Belo Horizonte designados a operacionalizar o controle sobre o comércio ambulante. As análises foram elaboradas com o intuito de compreender as ações de controle por meio dos auxiliares de fiscalização, trabalhadores que as implementam em suas "pontas", em interação constante com os principais públicos-alvo.

Para além de um estudo que priorize tipos organizacionais ou institucionais ideais ou fixos, a investigação, compreendida entre 2013 e $2016^{2}$, priorizou o levantamento de dados empíricos mediante o acompanhamento in loco das rotinas de trabalho ${ }^{3}$, além de entrevistas em profundidade com os funcionários terceirizados. Partindo das práticas de trabalho dos auxiliares de fiscalização enquanto "trabalhadores do controle", faz-se possível compreender a fiscalização como uma construção social multi-dimensional. Para isso, foi importante apreender as condições pelas quais os auxiliares ocupam os postos de trabalho e lidam com os seus públicos-alvo levando em conta, portanto, os aspectos estruturantes e de caráter subjetivo: expectativas; disposições; percepções dos conflitos; modos

2 Este texto é produto da pesquisa realizada no âmbito do mestrado pelo Programa de Pós-graduação em Sociologia da Universidade Federal de São Carlos (UFSCar), financiada pela Coordenação de Aperfeiçoamento de Pessoal de Nível Superior (CAPES), cujo resultado foi a dissertação intitulada "A construção de um controle negociado: o trabalho dos auxiliares de fiscalização da Prefeitura de Belo Horizonte" (Araújo Filho, 2016).

3 Este acompanhamento foi feito principalmente na região central de Belo Horizonte, onde pude presenciar a ação tanto de coletinhos azuis, quanto de agentes do Apoio. A fim de lograr melhor inserção entre os trabalhadores, me dediquei a seguir a rotina de poucos grupos para que pudesse permanecer por um tempo maior de contato. Ainda assim também me interessava conhecer a variedade de situações de trabalho (regiões, horários, atividades diversas); mas também atentei-me a conhecer relatos de auxiliares de perfis diferentes (tempo de serviço, idade etc). 
de significarem o próprio emprego e as tarefas desempenhadas; códigos morais mobilizados etc. Não somente a posição que estes sujeitos ocupam no mundo do trabalho informa sobre seus lugares sociais, mas também em outros campos da vida social. Como veremos, a perspectiva de gênero foi imprescindível para o desenvolvimento das análises.

Desta forma, um dos investimentos da pesquisa foi a reconstituição das trajetórias sócio-laborais dos auxiliares de fiscalização mediante entrevistas em profundidade. Esta metodologia corresponde a uma perspectiva sociológica que busca compreender de forma cruzada as dinâmicas mais abrangentes acerca do mundo do trabalho e das construções de gênero, interconectando elementos dos ditos "mundo privado" e "mundo do trabalho" (Cabanes, 2011; Guimarães; Georges, 2009; Hirata; Kergoat, 2007). Diz respeito, portanto, ao que está por trás das disposições assumidas pelos trabalhadores diante dos papéis delegados nessa configuração operacional. Os aprendizados estão inscritos em suas práticas laborais e dão sentido à produção de um tipo peculiar de controle social por intermédio dos papéis que desempenham nas linhas de frente.

E, afinal, quem são estes trabalhadores? Esses auxiliares são agentes do setor municipal que atuam cotidianamente nas ruas da cidade em contato direto com os comerciantes ambulantes. Trata-se de um trabalho terceirizado e subalterno, além de exclusivamente masculino.

Na prática cotidiana, a categoria dos auxiliares se divide em duas frentes ${ }^{4}$ principais da fiscalização urbana, pelas quais são a principal força de trabalho: os plantões e as ações de apreensão de mercadorias, realizadas pelas chamadas equipes de Apoio (ou simplesmente Apoio). Cada uma destas frentes constitui grupos de trabalho e sociabilidade distintos, cujas funções organizacionais se articulam para a composição da mecânica operacional mais geral da fiscalização.

O plantão é a modalidade pela qual é envolvido o maior número de auxiliares. Neste caso eles são apelidados de "coletinhos azuis" ou "azuizinhos", com referência ao uniforme que usam. Esta modalidade dá forma à estratégia de vigilância constante e ação ostensiva nas ruas de Belo Horizonte, na qual os auxiliares se tornam os "olhos e ouvidos" da Prefeitura. Melhor dizendo, devem ver e serem vistos, afinal sua presença nos espaços serve para coibir as atividades

4 Importante deixar claro que os trabalhadores que ocupam esta posição podem ser delegados a participar de outras tarefas, principalmente dentro do campo da fiscalização urbana, que abarca diferentes áreas, como posturas, obras, vias urbanas, limpeza urbana e controle ambiental. Além das modalidades que apresentarei, aos auxiliares de fiscalização podem ser alocadas a algumas intervenções operadas pela Prefeitura, como participar da montagem e desmontagem de barracas em feiras; recolhendo entulhos em vias; participando de abordagens a pessoas em situação de rua; carregando e descarregando materiais de caminhões; recolhendo faixas instaladas de forma irregular pela cidade etc. 
consideradas irregulares. A saber, a tarefa base dos coletinhos azuis é a realização de vigilância em um microterritório (quarteirões, praças, parques), cujo fim é a prevenção de atividades consideradas irregulares, como o comércio ambulantes.

Se em determinada região da cidade a presença dos ambulantes não se configura como uma preocupação constante (as "áreas limpas", como diriam os coletinhos azuis), o desígnio das equipes de auxiliares para os plantões serve para que esta área continue "limpa". Entretanto, não existem protocolos que orientem os modos de atuação desses funcionários nos espaços públicos. Para tanto, frequentemente interagem com os ambulantes, e de formas diversas, a depender de como definem a situação (Thomas; Thomas, 1928), seja orientando, expulsando, tentando convencer etc. Como frequentemente foi apontado nas entrevistas, em plantão, os auxiliares devem "saber conversar", devem ter "jogo de cintura" para manterem "as coisas em ordem".

A olhos estranhos, a relação entre auxiliares em plantão e ambulantes parece peculiar. Alguns dos próprios auxiliares chamam a tarefa de "enxugar gelo", referindo-se à sensação de trabalho sem fim ou mesmo sem propósito, uma vez que não detêm autoridade suficiente para realizarem apreensões ou assinarem as autuações. Por outro lado, podem apenas ameaçar os ambulantes a chamarem as equipes volantes incumbidas de realizarem as apreensões. Entretanto, como parte dos comerciantes ambulantes ${ }^{6}$ tendem a ser persistentes, essa relação é sempre negociada. Entre encontros e desencontros, disputas e tolerâncias, constrói-se um senso de rotina entre estes "trabalhadores do controle" e seu público-alvo que se inscreve nos modos negociados de funcionamento do plantão e, por efeito, da fiscalização como um todo.

Além disso, ressalto ainda, o senso de respeitabilidade e ética (entre trabalhadores pobres) que atravessa a constituição das sociabilidades da rua e que contribui para a continuidade tanto do trabalho dos auxiliares, quanto dos ambulantes. "Respeita meu trabalho que eu respeito o seu", ou "pode trabalhar, mas não fique aqui perto do meu plantão" são frases regularmente utilizadas nestas interações.

Quando o auxiliar em plantão nas ruas se percebe em circunstâncias desfavoráveis para o trabalho de coibição e negociação, seu último recurso ${ }^{7}$ é se comunicar

5 A saber, segundo o Código de Posturas de Belo Horizonte (Lei. 8.616 de 2003): "fica proibido o exercício de atividade por camelôs e toreros em logradouro público" (Art.118).

6 Em Belo Horizonte, ambulantes persistentes e que, desde a perspectiva da fiscalização, "dão mais trabalho", são denominados toreros. O termo origina-se da gíria local "torar" ou "fazer [algo] na tora", que designa justamente à obstinação destes vendedores em resistir às proibições e ações de controle (Araújo Filho, 2019).

7 Nota-se que a chamada funciona, muitas vezes, também como uma ameaça, quando ocorre na frente do ambulante, que o "convence" a se retirar imediatamente, sem que o Apoio precise de fato se deslocar ao local. 
com as equipes de Apoio pelo rádio $\mathrm{HT}^{8}$ que carregam consigo. Essas equipes devem, por sua vez, se deslocar até o local e intervir imediatamente (muitas vezes de surpresa), apreendendo as mercadorias e autuando o comerciante. Se a rotina característica do plantão deflagra uma significativa margem para a comunicação, pode-se afirmar que, o papel do Apoio - do outro lado dessa divisão do trabalho - é o oposto. Como colocaria Becker (2008), a apreensão das mercadorias seria a própria imposição de regras para esta dinâmica de controle social.

Cada equipe de Apoio se locomove por uma Kombi branca sem identificação, pronta para surpreender ambulantes desprecavidos. A equipe é composta idealmente por um fiscal, responsável por assinar o auto de apreensão; um policial militar, cuja função principal é garantir a segurança da equipe; e por um grupo de (normalmente quatro) auxiliares de fiscalização. Estes agentes comumente também auxiliam as ações de apreensão realizadas por Guardas Municipais que, a partir de 2016 (Decreto n. 16.211) também passam a gozar de autoridade para fazer apreensões autonomamente.

Em ambas os casos, são os auxiliares que, de fato, "pulam", "dão o bote" nas mercadorias expostas irregularmente à venda, as guardam nos invólucros de plástico transparente e, em seguida, as carregam para as Kombis. Haja vista que realizam o trabalho braçal das apreensões, são constantemente antagonizados com os ambulantes que os identificam como adversários. As reações violentas por parte dos ambulantes que sofrem as apreensões tornam-se frequentes, podendo até mesmo ocorrer ameaças e ações de vinganças que, consequentemente, se desdobram para além do ambiente de trabalho.

A comparação entre plantão e Apoio é inevitável e marca, inclusive, a hipótese de que a formação de identificações distintivas com as tarefas e corpos organizacionais são, por sua vez, causa e efeito de processos de socialização dentro e fora do trabalho. Haja vista a mecânica da implementação da fiscalização, as modalidades foram representadas pelos sujeitos como opostos, que conformariam qualidades e disposições distintas, expressas pela noção de que existiriam "perfis" ideais para cada papel desempenhado. A estruturação da implementação da fiscalização acompanha, e assim argumento que é reproduzida, por meio de dimensões de caráter subjetivo que conformam as disposições e os modos de relacionar-se com os públicos-alvo, inclusive desde a identificação desses sujeitos nos espaços públicos.

As seções que seguem destacam os principais aspectos que conformam e contextualizam a posição de auxiliar de fiscalização no mercado de trabalho,

8 Rádio hand-talk ou rádio transmissor portátil. 
chamando a atenção para como isso é significativo nos projetos de vida. Desta forma, destaco como estes aspectos projetam papéis a serem assumidos, tendo em vista que se trata de um típico trabalho masculino e subalterno.

\section{Considerações sobre gênero e trabalho}

Um ponto crucial para se compreender a função dos auxiliares é que se trata de uma atividade exclusivamente masculina. Segundo a gerência da secretaria responsável, "ser homem" é o pré-requisito básico exigido na seleção dos auxiliares. Vale comparar que, entre os fiscais, esta condição não existe: há tanto fiscais homens quanto mulheres no quadro de funcionários. $\mathrm{O}$ preenchimento dessas vagas se deu mediante concurso público, ao passo que, no caso dos auxiliares, acontece por meio de uma seleção aberta realizada pelas empresas prestadoras de serviço. Apesar de não haver justificativas formais acerca deste critério na seleção dessa categoria, fica claro que existe uma estruturação proposital baseada em certa expectativa sobre o que seria uma qualificação ideal de funcionários nessa posição, baseado, por sua vez, em uma clara ideia de papel masculino.

Olhando além do posto de trabalho, destarte, ressalto que se trata também de um ambiente de trabalho hegemonicamente masculino, isto é, no qual as construções de gênero masculinas encontram fácil encaixe e fluência. Isso se observa nos vários níveis hierárquicos, desde o âmbito de atuação dos auxiliares, policiais, supervisores e principalmente entre os fiscais ${ }^{9}$ chefes que se responsabilizam pela fiscalização sobre ambulantes. Mostrou-se evidente quando as fiscais (mulheres) foram sistematicamente apontadas por auxiliares ou mesmo outros fiscais (homens), ao grupo de fiscais que "não têm o perfil de trabalho de rua". Enquanto isso, os fiscais com "perfil de rua" foram todas as vezes atribuídos aos fiscais homens. ${ }^{10}$ Quer dizer, quando inseridas em um campo hegemonicamente masculino, mesmo as fiscais têm reduzidos os seus espaços de exercício de autoridade.

9 Vale destacar que a atuação dos fiscais em Belo Horizonte integra cinco áreas distintas - posturas, obras, vias urbanas, limpeza urbana e controle ambiental -, até então observadas separadamente por fiscais específicos. Por isso, são chamados de fiscais integrados e não trabalham exclusivamente em alguma área específica mas, em tese, circulam em várias delas. Ainda assim, isso não impede que os profissionais se organizem para que possam trabalhar prioritariamente em áreas que têm mais aptidão.

10 Como já ressaltado, a pesquisa não priorizou o conhecimento das rotinas e distinções dos outros grupos profissionais ligados à fiscalização, sobretudo daqueles pertencentes ao topo da cadeia hierárquica que conferem a outros agenciamentos e contextos de trabalho. Todo o contato que estabeleci com estes fiscais se deu enquanto estavam envolvidos com as tarefas desta frente específica (dentre tantas) da Fiscalização Integrada. 
Conquanto verifica-se a existência de diferenciações internas no corpo de funcionários, retomando a ideia já discutida acerca dos "perfis" associados às diferentes modalidades de trabalho, o que caracteriza o posto de trabalho dos auxiliares como um todo, é a ideia do gênero masculino como a única possibilidade para a suposta "natureza" do ofício e de suas tarefas operacionais. Tal concepção traz efeitos certamente definidoras para a maneira com que estes homens se socializam no trabalho, até porque os papéis de gênero são constantemente reforçados pelos modos como se auto-definem. Tudo isso influi, certamente, na maneira como participam do controle social e ajudam a elaborálo cotidianamente, tanto os coletinhos azuis, quanto os agentes do Apoio.

O que se observa é que o emprego de auxiliar de fiscalização faz parte de um nicho específico do mercado de trabalho, em que estão alocados geralmente, e não por acaso, homens das classes populares com baixa escolarização e pretensão salarial, como veremos em seção posterior. Diante disso, os postos de trabalho advindos de contratos de terceirização por órgãos governamentais/ estatais, como no caso a Prefeitura de Belo Horizonte, se inserem nesse mercado e aparecem aos trabalhadores como mais uma possibilidade de acessar o emprego formal - "ser fichado" - ainda que não ofereça grandes atrativos financeiros ou de estabilidade.

O fenômeno da terceirização do "trabalho do Estado" não é exclusivo do caso belo-horizontino, ou tampouco se manifesta apenas para os empregos majoritariamente ocupado por homens. Por isso, faz-se necessário discutir brevemente como a conformação dos postos de trabalho nas "pontas do Estado" refletem, à sua maneira, a divisão sexual do trabalho (Hirata; Kergoat, 2007). A cada contexto de implementação de serviços públicos, são reveladas mobilizações de papéis de gênero em encaixe com determinados setores, mas que também interferem na própria elaboração das práticas de trabalho.

Hirata e Kergoat (2007) destacam a divisão sexual do trabalho" como uma forma de divisão social do trabalho decorrente das relações de poder entre os sexos, e chamam a atenção para a sua centralidade, constituída histórica e socialmente, no sentido da manutenção das desigualdades sociais. Essa perspectiva teórica reitera que relações de classe e gênero devem ser pensadas como fatores estruturantes da sociedade, na medida em que estão sobrepostas. Em suma, quer dizer que as relações de classe são sexuadas, assim como as relações de gênero são perpassadas pelas relações de classe.

11 O cerne da ideia foi esboçado primeiramente por Engels (2002) em "A origem da família, da propriedade privada e do estado." 
A formulação de Hirata \& Kergoat (2007) diz respeito à dispersão desigual entre homens e mulheres no mundo do trabalho, o que está refletida na designação, delegação e na consequente naturalização de ofícios, profissões e atividades como sendo funções próprias de homens ou mulheres. De forma dinâmica entre estrutura e prática, este engendramento social está assentado (e assim se reproduz) em opostos sexuados: espaço público e privado; produção e reprodução; "trabalho masculino" e "trabalho feminino". Ele "rebaixa o gênero ao sexo biológico, reduz as práticas sociais a 'papéis sociais' sexuados que remetem ao destino natural da espécie" (idem, p. 599).

O modo de ordenamento sexuado e desigual está expresso no mundo do trabalho como um todo, e pode ser identificada, assim, dentro de campos mais específicos. Quando analisamos as camadas de trabalhadores do Estado que lidam diretamente com o público, observa-se que os empregos tipicamente masculinos proporcionam atividades voltadas para as dinâmicas de uma esfera pública ("para fora") - como fica claro pelo caso dos auxiliares de fiscalização, que lidam com a vigilância, a imposição de regras, o controle de práticas, com "a rua". Enquanto isso, os empregos tipicamente femininos estão voltados para o "lar", a esfera privada ("para dentro") - como as trabalhadoras do cuidado12, que tem nos vínculos familiares seus motes de significação (Soares, 2012; Molinier, 2012).

Afinal, chamo a atenção para uma "divisão sexual do trabalho do Estado" fica visível, a princípio, pela distribuição diferenciada de homens e mulheres dentro dos grupos operacionais, e mais precisamente "a nível de rua" (Lipsky, 1980), isto é, como interfaces perante os públicos. Além disso, faz refletir sobre como as diferentes frentes da governança são também institucionalmente sexuadas, intervindo assim nas sociabilidades e nos modos de contato com o Estado: seja no sentido do acesso aos direitos sociais, seja como alvo do controle.

O foco está posto, portanto, sobre os modos de interações que envolvem a(o)s agentes nas "pontas" do Estado diante das construções de gênero ali assentadas como seus condicionantes. Tendo como base um ponto de vista interacional, essa divisão também se expressa no trato com o outro; isto é, nos modos diferenciais de comunicação interpessoal ou na gestão das emoções

12 Mais especificamente, lembrar das Agentes Comunitárias de Saúde como parte deste grupo, categoria profissional exclusivamente feminina no contexto das chamadas "novas políticas sociais" (Lima; Moura, 2005; Lima; Cockell, 2008; Georges; Santos, 2012, 2014, 2016). Ela se dá, principalmente, enquanto tradução dos "códigos institucionais" dos programas às famílias atendidas, o que se faz possível devido à proximidade - comunitária, mas sobretudo social/de gênero - entre as profissionais e as suas beneficiárias (Georges; Santos, 2012, 2016). 
(Hochschild, 1983). A experiência dos agentes da Prefeitura de Belo Horizonte está repleta de situações em se exige um tipo de trabalho emocional específico, também marcado pela necessidade da "boa medida" nas ações: certo equilíbrio entre o profissionalismo e o tato interpessoal. Se por um lado os trabalhos femininos exigiriam demonstração de ternura, gentileza, delicadeza, intuição, sensibilidade e doçura, já nos trabalhos masculinos, as tarefas exigem graus de agressividade, rudeza, dureza e frieza (Soares, 2013). Isso fica ainda radicalizado no contexto do "trabalho do controle", em que o conflito, muitas vezes, se projeta ou se materializa em forma de violência física; mas também, aos seus modos, no esforço dos auxiliares em plantão em praticar um controle negociado.

É preciso estar atento às particularidades empíricas, sobretudo no que diz respeito aos efeitos reais (muito ou pouco visíveis) dessa estruturação para a dimensão das práticas. Desta forma, retornamos o foco à análise dos auxiliares de fiscalização para observar como este posto de trabalho está em constante ativação enquanto um trabalho masculino. Isso ocorre tanto pelos aspectos que o posiciona e o legitima institucionalmente, mas também informado dinamicamente pela apropriação dos trabalhadores às práticas de trabalho.

\section{Circuitos, mercados de trabalho e prospecções}

A metodologia de análise de trajetórias de vida lançada mão nesta pesquisa possibilita o entrelaçamento das dimensões do trabalho com as dimensões do privado, de forma a imbricar os pontos de vista subjetivos a conformações sociais em outros níveis. $\mathrm{O}$ foco está posto desde a realização das entrevistas em como os sujeitos se conduzem, se percebem e se projetam em suas atividades no mundo do trabalho, de forma que seja conferir legibilidade às motivações, expectativas e disposições. Isso demonstra, de forma mais geral, que pelas trajetórias nos deparamos com "mediações e relações de força que tecem, de formas nem sempre evidentes, os campos de possibilidades, e também os bloqueios para o acesso e efetivações de possibilidades de trabalho e condições de vida." (Telles, 2006: 88)

Por meio disso, não pretendo, logo, encerrar estes sujeitos em classificações premeditadas, mas, como apontado, situá-los em construções e processos sociais mais amplos com base em uma série de cruzamentos referenciais que ficam demarcados ao longo da elaboração das narrativas. Afinal, são estas construções sociais que dão sentido às ações individuais e às racionalidades que conectam o posicionamento nas composições familiares, as caminhadas pelo mundo do trabalho, ao mesmo tempo que os encaixes com os modos operacionais da fiscalização. 
Primeiramente, é preciso levantar alguns pontos que situam o posto de auxiliar de fiscalização no contexto das transformações contemporâneas do mundo do trabalho. Argumento que a naturalização da pouca prescrição e maleabilidade de tarefas; e a frouxidão dessas tarefas perante objetivos institucionais mais amplos são expressões da "institucionalização do vago" (Azais, 2010), característica das tendências contemporâneas do assalariamento. Em outras palavras, estes trabalhadores são pressionados a se tornar trabalhadores flexíveis subalternos, prontos a realizarem o "trabalho sujo"13 (Hughes, 1958) da fiscalização. Essa flexibilização também se manifesta em outros níveis, para além da correspondência com as normas de contratação previstas pelas normas da Consolidação das Leis do Trabalho (CLT). Apesar de se tratar de um "trabalho fichado", os trabalhadores experienciam uma instabilidade típica da "zona cinzenta do assalariamento" (Bureau et al, 2019) que mistura elementos do trabalho protegido e desprotegido, com base em uma inclinação aos modos informais de relação de trabalho. Por exemplo, apesar de serem formalizados e trabalharem para o Estado, sua permanência no emprego depende em última instância da validade dos contratos da Prefeitura com a empresa terceirizada.

De forma mais geral, esta tendência contextualiza-se pelo fenômeno contemporâneo das terceirizações dos serviços públicos e da descentralização da implementação de políticas estatais (Lima; Cockel, 2008). Isto é, quando, por fim, o próprio Estado reconfigura-se burocraticamente e passa a se tornar mais um possível provedor de postos de trabalho subalterno e precarizado (Georges; Rizek; Ceballos, 2014).

De modo geral, este é o pano de fundo para estas narrativas de trajetórias laborais repletas de inseguranças, incertezas, mudanças de emprego, conciliação de várias atividades remuneradas, saídas pela informalidade etc. Tudo isso está conectado e compreendido em uma realidade de baixos salários e baixíssimas expectativas de ascensão social, na qual a subalternidade se expressa de forma naturalizada na fala dos interlocutores.

13 Por "trabalho sujo" não me refiro a práticas criminosas, como extorsões, esquemas de corrupção, "venda de pontos" etc. Inclusive, há de se ressaltar que, uma vez que a pesquisa se deu com base nos trabalhos dos auxiliares como mote para a empiria, não foi possível supor a existência de "mercados de proteção" (Misse, 2002) como fator de organização do comércio de rua em Belo Horizonte. 0 tipo de discricionariedade frágil (Araújo Filho, 2016) conferido ao nível operacional dos auxiliares não é suficiente, portanto, para que estes sujeitos operem mercados de pontos de venda, justamente porque sua posição representa a institucionalização da negociação das regras. Isso não quer dizer, no entanto, que os auxiliares não participem de trocas de favores ou pequenos subornos, que estariam contidas no âmbito das resistências (Scott, 2011) e negociações cotidianas: o que pode ou não ser tolerado. Desta forma, este tipo de prática certamente não ocorre de forma sistemática e regulatória para a organização do comércio de rua no Centro de Belo Horizonte. 
Por meio das percepções que têm os entrevistados acerca do emprego atual, apesar de se tratar de um trabalho "pela Prefeitura", o que se nota é que o apresentam como um "emprego normal" (Lallement, 2019). Isto é, trata-se de uma posição ou uma experiência de trabalho que potencialmente não gera rupturas em suas trajetórias laborais. Ao contrário, aparece como continuidade, tendo em vista as outras atividades igualmente subalternas e "normais" do passado e presente, mas também socialmente percebidas, pela identificação junto aos pares de seus lugares sociais de destino.

Apesar de haver certo reconhecimento compartilhado acerca da importância de uma aptidão (ou "perfil") para a realização de determinadas tarefas como auxiliar de fiscalização, a entrada desses sujeitos para o emprego não se dá por uma demanda de qualificação específica desde os contratantes. No geral, as aptidões se manifestaram como adequação e encaixe às tarefas com o decorrer do tempo de serviço, dado o processo de aprendizado prático e de variadas identificações de cunho subjetivo. É preciso dizer que as funções assumidas pelos auxiliares são bastante maleáveis e com pouca prescrição formal, dada a grande margem de desígnio dessa mão-de-obra para demandas diversas.

Por outro lado, o que os entrevistados alegam ter chamado a atenção na vaga de emprego na fiscalização foi a possibilidade de um serviço "tranquilo", "normal", ou "como outro qualquer". O caráter de normalidade diz respeito, por sua vez, às experiências nos trabalhos entre os quais eles e seus pares circularam e ainda circulam, mesmo sem se manterem em expectativa de ascenção. De modo geral, a preponderância desse pragmatismo sobrepuja (ou pelo menos esconde) uma narrativa de encaixe e desencaixe de suas identificações pessoais com relação a suas trajetórias laborais. Na medida em que são compelidos pela urgência de estarem empregados, ou pelo menos recebendo alguma renda fixa, lhes parece natural que se engajam em atividades que percebam como genéricas.

No caso daqueles que ingressaram antes de 2013, a jornada reduzida ( 36 horas semanais), muitas vezes, foi um fator atrativo, já que representava a possibilidade de manter uma renda fixa (ainda que baixa) em um trabalho formal e ainda poder acumular outras atividades, como algum outro emprego, "bicos" e/ou estudos. Com o aumento da jornada para 44 horas semanais (acompanhado do aumento de salário proporcional), alguns inclusive pediram demissão por não conseguirem conciliar com outras atividades remuneradas que conferiam maior rendimento proporcional. Os demais, por outro lado, escolheram a estabilidade do salário fixo, como Douglas (23 anos, atua no plantão) que trabalhava como entregador para uma lavanderia; Geraldo (52 
anos, atua como Apoio) e Raimundo (34 anos, atua como Apoio) como garçons em restaurantes; sem contar Erik (25 nos, atua no plantão) que, nessa época, ainda persistia cursando Engenharia Mecânica antes de interromper por não conseguir pagar as mensalidades.

Para a análise de trajetórias, também interessa compreender os sentidos do que se prospecta e idealiza. Por isso, outro fator importante para a caracterização geral desses relatos, foi a recorrente indicação do concurso para Soldado da Polícia Militar como uma possibilidade de "subir na vida", denotando a ideia de "escape" ao traçado comum dessas trajetórias. Muitos já tentaram o concurso, muitos outros afirmam pelo menos interesse. Mesmo tendo ocorrido mais entre os auxiliares mais jovens, pode-se dizer que essa identificação compartilhada aponta para a conformação de um público que convenciona certo tipo de estratégias de vida e que, potencialmente, traça certo tipo de carreira.

Sobretudo, esse tipo de identificação coletiva situa o grupo profissional em meio a um campo de trabalho convencionalmente masculino e de baixa remuneração, ligado à vigilância e segurança, seja nos setores privado ou público. Configura-se assim como um circuito de mercado que não lhes é exclusivo, porém é pelo qual esses trabalhadores caminham com mais facilidade entre trabalhos ("fichados" ou informais; fixos ou temporários), por meio de redes de indicação, compartilhamento de informações e currículos.

Dentro desta lógica, o concurso para se tornar Soldado da Polícia Militar parece a maioria destes homens como uma oportunidade excepcional (relativamente às inserções usuais) de galgar uma carreira promissora e estável - financeiramente ou em termos do reconhecimento social. O ofício foi indicado por alguns como próximo de suas aptidões e interesses, mas também é idealizada tanto no que diz respeito às condições de trabalho, quanto à maior clareza de atribuições, isto é, "fazendo o certo", como explicou-me Douglas no relato a seguir.

Douglas: Primeiro [motivo] é o salário, e outro porque... ah, é uma carreira. O serviço também acho que não é ruim de fazer não. Você está fazendo o certo. Tarcísio: Como assim?

Douglas: Ah, você vai ter uns problemas e tal, mas você vai ter... tipo assim, deixa eu ver como é que eu vou te explicar. Você vai fazer cumprir a lei. Você vai fazer o seu serviço.

Para muitos auxiliares de fiscalização, o futuro como policial passa a ser uma abstração de futuro conveniente e, sobretudo, plausível enquanto estratégia de ascensão social, o que se reforça porque, como já mencionei, convivem 
com policiais no contexto de trabalho ${ }^{14}$. Esta representação reflete uma espécie de racionalização de possibilidades, que leva em conta a maneira como eles se enxergam dentro das vicissitudes do mercado (por meio de suas capacidades individuais, mas também com relação aos valores compartilhados); e as expectativas individuais - porém de fundo social - acerca do sentido de suas trajetórias.

$\mathrm{O}$ caso de Erik é emblemático. Em sua entrevista, apresenta o sonho de se formar em Engenharia, um objetivo que ainda lhe parece distante, apesar de já ter iniciado os estudos. Posteriormente, em outro momento, em um intento por ser mais "realista", também diz ter vontade de ser aprovado no concurso para policial. Diante de sua trajetória e origem social, mas também entre os dois caminhos que abstrai para o futuro, o jovem Erik identifica seus "lugares sociais" em sua percepção das probabilidades.

Por outro lado, por meio da perspectiva que as trajetórias oferecem, é possível perceber que o emprego como auxiliar de fiscalização faz parte de um nicho do mercado de trabalho bastante amplo e genérico pela diversidade de tipos de trabalho. Este posto se destina a homens das classes populares (normalmente moradores dos bairros de periferia), com baixa escolaridade, com baixa pretensão salarial, pouco profissionalizados. Portanto, independentemente se estão situados em circuitos específicos dentro de um mercado de trabalho, a sucessão de empregos, "bicos", empreitadas e atividades econômicas variadas reitera o que parece ser uma condição social própria da trajetória desses homens trabalhadores que "se viram" e sempre "se viraram".

Diante da perspectiva das zonas cinzentas do assalariamente, não há nada de controverso na história de Erik, por exemplo, que entrou há poucos anos no mercado de trabalho e já experimentou atividades como a de trabalhador rural, embalador, estoquista, vendedor em loja de sapatos e, agora, auxiliar de fiscalização; ou o experiente Geraldo que foi pintor, pedreiro, eletricista, garçom, auxiliar de corte de mármore, embalador de remédios, office boy; ou mesmo Renato (6o anos, atua no plantão) que mesmo tendo trabalhado quase que exclusivamente como carregador de cargas, passando por várias empresas, "se fichou" na Prefeitura pela expectativa de acumular seus últimos anos como contribuinte regular do INSS ${ }^{15}$, trabalhando em algo menos fisicamente desgastante em seus últimos anos antes da sonhada aposentadoria.

14 Lembro-me de presenciar, dentro da Kombi do Apoio, um auxiliar demonstrando curiosidade com o revolver do policial militar que acompanhava as ações. Interessado, o auxiliar fazia perguntas sobre o trabalho policial e pedia para segurar a arma, o que foi negado constrangedoramente pelo policial que considerou o pedido como uma brincadeira. 
Ressalto a importância para olhar a sucessão de atividades como um aspecto central para a formação das subjetividades expressas pelas trajetórias narradas. A circulação frequente entre trabalhos não necessariamente confere mobilidade social ou mudança constante de estratégias de vida. Contrariamente, denota a naturalização da racionalidade da "viração", principalmente porque normalmente figuram, ou pelo menos assim se assumem, como provedores em suas famílias. Geraldo, por exemplo, começou a trabalhar ainda criança e, desde então, acostumou-se em acumular empregos e bicos de todo tipo. Segundo ele, "trabalhando dia e noite, o meu está garantido!" e "não pode parar né. Se parar, enferruja", referindo-se à probabilidade de não parar de trabalhar mesmo depois de se aposentar.

Desse modo, atribui-se sentido às surpreendentes histórias frequentemente relatadas sobre conversões de auxiliares de fiscalização para vendedores ambulantes, e vice-versa. Guardadas certas especificidades, ambas as atividades estão contidas no horizonte de saídas plausíveis, e até mesmo moralmente aceitáveis, para homens pobres das cidades brasileiras. Douglas conta com naturalidade sobre seu pai que trabalhou por muitos anos como vendedor de balas no Centro e depois passou a atuar como coletinho azul.

Tarcísio: Como é que era para ele ter sido camelô e depois ter sido parte da equipe de fiscalização?

Douglas: Ah, normal, porque na época aqui que ele chegou, ele nem conhecia ninguém. Ninguém sabia não. Porque na época não tinha fiscalização igual tem hoje. Na época era praticamente liberado. Tem muitos anos atrás.

Aspectos articulados à racionalidade da "viração" são a capacidade de conciliação das atividades acumuladas, de mobilização de redes de indicação para trabalhos, de negociação de demissões e direitos trabalhistas com os patrões. Imersos em uma "zona cinzenta" para além das referências do trabalho assalariado, os sujeitos circulam com certa destreza pelo universo do trabalho precário, entre experiências pela informalidade, subcontratações de todo tipo e empregos com registro formal. De formas diversas, apreendem sua condição como trabalhadores também pelos direcionamentos estratégicos necessários para a "viração" desde a socialização primária (Berger; Luckman, 2004), como uma herança de classe aprendida desde as relações familiares principalmente (Cabanes, 2011).

Por este ponto, ressalto a importância que as referências familiares masculinas tiveram para a construção dos relatos pelos entrevistados, em torno de 
como se situam e caminham pelo mundo do trabalho. Esse fator fica explícito dentro das narrativas desde a iniciação no mundo do trabalho, como se ilustra pelo exemplo de Douglas e seu pai que o inseriu na maioria de seus empregos; como rede primária de orientação e indicações, como no caso de Geraldo e seu irmão mais velho que lhe insere em vários "bicos" noturnos e de final de semana; ou, de forma mais abrangente, no que diz respeito à transmissão de valores, como aponta Raimundo e a centralidade que confere ao peso de sua "criação" para sua postura como trabalhador e homem de família:

Tarcísio: O fato do seu pai ser militar, você acha que isso teve muita influência na sua vida, na sua criação?

Raimundo: Teve. Meu pai me ensinou a respeitar as pessoas, quando uma pessoa está falando você espera a pessoa acabar de falar para a gente chegar e falar. E lá em casa era assim: se chegou uma pessoa na casa e a gente não cumprimentou, não levantou e deu benção no meu pai e deu um beijo no rosto da minha mãe, apanhava. "Vocês me dão licença que eu vou tomar um banho ali". Tinha que pedir licença. "Dá licença que eu vou me retirar aqui, vou estudar... vou trabalhar..."

Tarcísio: E assim você cria seus filhos também?

Raimundo: Assim que crio meus filhos. Não crio meus filhos batendo, gritando, espancando. Chegou da escola, "me dá sua mochila, deixa eu ver o que você fez, que exercício tem para você fazer? Se tiver algum exercício que você não sabe fazer, vamos lá sentar na mesa lá. Acabou de fazer? Vamos lá lavar a mão e tomar um café. Vai lá tomar um café lá." "Ah, papai, quero brincar.", "Pode. Tantas horas e dentro de casa. Com quem você está indo? Onde você vai?", "ah, vou na casa de..." "pode. Na hora que você chegar lá você pede para ela me ligar”. Então, acho que estou fazendo o melhor para os meus filhos, no meu modo de vista. Mas muitas pessoas, que nem as minhas cunhadas, falam que eu sou muito rigoroso com eles, sou muito rígido com eles. A sobrinha da minha mãe com 13 anos já estava grávida. Meu filho tem 12, tenho uma filha de 5 . Daqui há pouquinho está mocinha. Meu menino tá rapazinho. Se junta com os meninos e vai usar droga, vai fazer coisa errada... Aí eu não quero. A educação que eu tive, eu quero passar para eles.

Como vimos nesta seção, por meio da análise das trajetórias, é possível delinear algumas das dinâmicas e estruturações pelas quais as vidas de trabalho estão assentadas, incluindo a passagem e atuação no posto de auxiliar de fiscalização. O esforço foi, portanto, situá-los por seu grupo profissional 
dentro de um panorama mais geral de mercado de trabalho e em termos de estruturações mais amplas como classe/origem social, o que está inscrito nos sentidos que atribuem ao trabalho em suas variadas formas e expressões. Nesse sentido, chamam atenção alguns aspectos relevantes dessa caracterização, referentes ao peso das construções de gênero, tanto no que se refere a uma segmentação estrutural das atribuições, quanto às formas de agenciamentos.

\section{Fabricando auxiliares de fiscalização: formas de apropriação dos papeis de gênero}

Seguindo a proposta analítica acerca da imbricação de categorias de trabalho e gênero, ressalto, nesta seção, como os papéis de gênero são desempenhados e podem servir como motes para a compreensão do funcionamento da fiscalização "ao nível de rua", dependente do contato direto com os públicosalvo (Lipsky, 1980). Para ir além da associação do "trabalho do controle" como trabalho masculino, é preciso compreender como este aspecto estrutural se delineia pelas características próprias do expediente da fiscalização de rua. Isto é, trata-se de compreender os sentidos da delegação do "trabalho sujo" (Hughes, 1958) - perigoso, de atribuições imprecisas, físicamente desgastante - para este grupo de funcionários terceirizados.

Faz-se preciso apontar que não há determinismo com relação à associação do gênero masculino ao trabalho do controle (policiais, seguranças, porteiros, soldados, fiscais, por exemplo), uma vez que existe algum espaço, ainda que limitado, para as mulheres nesses segmentos do mercado de trabalho. Trata-se de indicar que determinadas atividades parecem se convencionar enquanto reflexos de processos mais amplos de construção do gênero na sociedade. Dentro das organizações, aspectos de gênero são definidores para a delimitação e designação de tarefas, atividades, sociabilidades, hierarquias etc.

A influência do militarismo para a fiscalização sobre ambulantes é um dos pontos centrais para compreender como se dá a intersecção entre as disposições tipicamente masculinas; ao mesmo tempo em que dão forma e sentido aos propósitos institucionais. Sem me aprofundar nesta discussão, é preciso salientar que vários postos de comando na fiscalização são ocupados por oficiais militares reformados; além disso, os modos estratégicos de dispersão territorial também são desenhados de forma a se alinhar com as operações da Polícia Militar de Minas Gerais. Decorre, portanto, que essa permeabilidade institucional se faz desde a elaboração estratégica projetadas pelos estratos superiores; à influência sobre as subjetividades dos operacionalizadores nas ruas.

Em pesquisa sobre o Exército Brasileiro, Rosa (2007), sob a ótica bourdieusiana, ressalta a existência de um campo militar, em que é possível identificar 
a emergência de um habitus correspondente e operante, o habitus militar. O protagonismo dos homens neste campo se dá enquanto elaboradores das regras do jogo. Em outras palavras, é possível dizer que jogam o seu próprio jogo com vistas na reprodução do mesmo. $\mathrm{O}$ autor discute sobre a associação entre o habitus militar e o habitus masculino, e diz que a combinação "Homem-Militar" torna-se naturalizada, inscrita na "ordem das coisas" (Bourdieu, 1999, Wacquant, 2002, apud Rosa, 2007). Esse quadro se manifesta quando se traduz em violência simbólica dentro da organização. Segundo o autor, as mulheres ${ }^{16}$ que, por sua vez, tiveram uma entrada efetiva no Exército Brasileiro apenas recentemente, acabam participando do campo apenas mediante certa "conversão" subalternizada.

$\mathrm{O}$ atrelamento de papéis de gênero à elaboração de determinados ofícios se torna, portanto, uma representação coletiva que se materializa pela reprodução de padrões de condutas, de discursos, expectativas compartilhadas e representações normativas que sustentam as instituições. Nessa perspectiva, autore(a)s como Poncioni (2005), Storani (2010) e Muniz (1999) apontam que as narrativas de justificação do trabalho policial (militar) são determinadas por simbologias e formas de agir que resultam e se sedimentam em um ethos guerreiro (combatente, viril, masculino). Reproduz-se, desta forma, padrões de comportamento que legitimam simbolicamente o trabalho do policial, à vista de todos, encorajando a agressividade como fator necessário para o cumprimento de suas obrigações públicas; ao mesmo tempo, em que se afirma enquanto homem (Poncioni, 2005).

No caso do campo da fiscalização, a ideia de habitus militar ou ethos guerreiro encontra-se diferencialmente difusa enquanto sistema normativo e de valoração, que produz efeitos gerais, mas que também alimenta crivos e distinções internas importantes. A inclinação à atitude policialesca e combativa, próximas de um ethos guerreiro, fica evidente principalmente por meio do trabalho das equipes de Apoio. Como já caracterizado, o Apoio tem a sua origem e seu funcionamento bastante conectado a uma espécie de mutualismo construído entre a fiscalização e a Polícia Militar, meio pelo qual, na prática, os agentes de Apoio aprendem modos de operação, códigos, gestos e desenvolvem, assim, sua autonomia no trabalho (Terssac, 2012). A fala a seguir demonstra como as tarefas da fiscalização na rua chega a se confundir com a dos policiais.

16 Em uma pesquisa sobre a entrada das mulheres na Polícia Militar paulista, Denari (2017) revela que à elas, normalmente, são separadas funções de menor prestígio segundo a lógica da sociabilidade e das hierarquias policiais dentro da organização. Estas funções normalmente não estão ligadas ao combate direto à criminalidade, mas a funções paralelas como suporte administrativo, relacionadas ao policiamento comunitário ou ao care. 
Tarcísio: E você já pegaram ladrão assim na rua?

Raimundo: Nossa Senhora, muito! Muito, muito. Às vezes a gente pega, às vezes é o polícia que fala "me ajuda aqui, na abordagem aqui", a gente só cerca assim "fica quieto aí, fica quieto aí!" O Vando, o Vanilson, o Paulete, o Welington, o Albert também, os outros meninos, [...] eles pegam mais porque eles trabalham à tarde, e à tarde tem mais roubo, que é a hora que o pessoal está saindo do serviço, estão cansados né, aí esquecem o telefone assim [aponta para o bolso de trás da calça]...

Tarcísio: Mas esse negócio de pegar ladrão... os seus chefes estão de boa com isso?

Raimundo: Tá, tá de boa.

Tarcísio: É arriscado né...

Raimundo: Às vezes eles falam "gente, não mexe não porque é ruim..." Porque é assim, a gente é uma equipe. Se o PM pede a ajuda da gente, a gente ajuda, porque quando a gente pede a ajuda dele ele ajuda a gente né.

Essa aproximação se evidencia, de modo geral, enquanto racionalidade operante nesta frente da fiscalização, inscrita desde a formulação dos discursos em torno da intervenção direta; da incorporação de responsabilidades sobre certa "ordem pública”; a identificação frequente de inimigos/adversários; a territorialização do espaço público e até mesmo a aceitação da violência física como fator inerente ao trabalho da fiscalização desempenhada nos espaços públicos ${ }^{17}$.

Deste modo, naturalizam-se as situações de violência como próprias do âmbito das responsabilidades individuais, tanto as agressões praticadas quanto as sofridas ${ }^{18}$.

Raimundo me mostra também uma cicatriz que tem no tórax, resultado de uma facada que tomou durante um conflito com camelôs, após uma ação de apreensão arriscada perto da Rodoviária. "Já levei paulada, pedrada,

17 Algumas reportagens, de períodos e jornais diferentes ilustram o argumento, como "Fiscais que lidam com ambulantes revelam clima de insegurança e medo" ilustra o argumento (Lopes, 2015); "Camelôs e ambulantes reclamam de violência de guardas durante fiscalizações" (Oliveira, 2017); "Briga entre camelôs, policial e fiscais termina com detidos em BH" (G1, 2019).

18 Este é um dos fatores mais flagrantes da situação de precariedade do emprego como auxiliar de fiscalização. Como são terceirizados, o Poder Público se isenta da responsabilidade de lidar com as situações de violência, enquanto a empresa contratante garante pouca resposta efetiva que assegure os trabalhadores. Enquanto a Prefeitura se isenta de algumas responsabilidades por não ser contratante, os auxiliares evitam ao máximo cobrar ou pressionar a empresa por medo da demissão. Quando se envolvem em brigas com ambulantes, os auxiliares são levados à delegacia e respondem às agressões como civis comuns, descontextualizados de sua situação de trabalho, diferente do que ocorreria com fiscais ou policiais militares em serviço como funcionário públicos protegidos. 
facada", conta espontaneamente logo no meu primeiro dia acompanhando o trabalho na Kombi da companhia. Alan confirma o fato de que estejam vulneráveis às agressões e as situações de violência na rua, mas faz questão de dizer que não deixa barato: "Tem vez que eu apanho, mas quando é assim, eu mais bato do que apanho." [extrato de caderno de campo]

A racionalidade (masculina, portanto) própria de uma representação dura e estrita acerca de suas atribuições e sua participação ativa no controle social se generaliza dentro do campo operacional da fiscalização uma vez que cria repertórios discursivos e hierarquizantes. Aparta-se um suposto "controle real" do Apoio, à etapa do trabalho de vigilância e negociação realizado nos plantões. A tarefa da vigilância passa a ser vista internamente como a parte fraca, vulnerável, impotente e passiva do processo. No contexto da fiscalização em Belo Horizonte, por mais que as ações de apreensão dependam, em grande medida do trabalho ostensivo feito pelos coletinhos azuis, o que se observa é a invisibilização desses, em detrimento de uma exaltação da importância e da efetividade das apreensões de mercadorias.

Durante meu contato com o campo, percebi que existe uma grande distância (e uma suposta hierarquia de status) entre as duas modalidades de auxiliares - coletinhos e Apoio - , que parecem opostas, pelo ponto de vista das representações que elaboram de si e sobre o outro. A começar, os auxiliares que compõem as equipes de Apoio em curso regular de rotina não se reconhecem pela mesma denominação dos demais: como auxiliares. Como não usam uniformes ou qualquer tipo de identificação, muitas vezes, precisei perguntá-los se eram auxiliares, já que se confundiam com os seus superiores ${ }^{19}$ que também trabalham à paisana, usando calça jeans, camiseta, tênis/sapato. Ao conhece-los, apresentam-se como Apoio.

Apesar de receberem o mesmo salário, trabalharem sob a mesma carga horária e terem o contrato de trabalho assinado da mesma forma, agentes do Apoio e coletinhos azuis frequentemente destacam suas diferenças relativas aos procedimentos, mas também à valoração das condutas. Mais do que isso, percebe-se que o discurso de identificação para com as tarefas do trabalho passa pela comparação com a tarefa do outro, como fica claro no extrato de caderno de campo a seguir.

Alan [agente do Apoio] conta que essa equipe é resultado de muita "peneira", afinal, "muitos desistem porque não aguentam a pressão", o ritmo e os riscos da atividade, e então pedem transferência para o plantão. Alan relata

19 Certa vez, Adilson sinalizou que percebe, enquanto supervisor ainda novato, que os agentes do Apoio costumam ser mais próximos e ter mais respeito ("ter mais moral”) dos fiscais e gerentes do que os próprios supervisores, que, obviamente, estariam acima dos auxiliares dentro da hierarquia oficial. 
que muita gente não entende porque ele continua nesse trabalho, e ele responde que é por que "gosta da adrenalina" e que não suportaria o trabalho dos azuizinhos no plantão, pois julga ser "muito parado". Diz também que sentiria certa sensação de impotência diante dos conflitos com os camelôs: diferente do Apoio, os outros auxiliares "não podem reagir de nenhuma forma”, a não ser chamando o Apoio e a Polícia Militar como último recurso. [...] Disse que o trabalho no Hipercentro é "muito difícil", mas que eles têm conseguido bons resultados. Raimundo [agente do Apoio] me mostrou uma foto das mercadorias da última apreensão que realizaram com ambulantes, segundo ele a maior apreensão de cigarro contrabandeado já realizada em Belo Horizonte. Também havia uma foto tirada de uma espécie de cartaz colado na sede da fiscalização, exposta em reconhecimento do feito; junto à foto da apreensão e a outra de todos os responsáveis pela ação. Pedi as fotos para Raimundo que não se incomodou em me enviar utilizando o bluetooth do celular. [extrato de caderno de campo]

Como Alan (26 anos), frequentemente, os agentes do Apoio destacam o sentimento de empolgação de estar à frente das apreensões, assim como o orgulho por encararem tarefas que consideram difíceis, além da sensação de potência por estarem nas linhas de frente; posto em paralelo à impotência e ao tédio que apontam para caracterizar o trabalho no plantão.

Essa hierarquização se legitima também por meio do reconhecimento dos superiores, demonstrando que estes valores não estão restritos. Atenção para a forma com que Raimundo narra sua passagem do plantão para o Apoio, como se fosse uma ascenção profissional e um episódio de inflexão para sua trajetória.

Raimundo: Eu entrei aqui para ficar de colete, que nem os meninos do plantão né. Quando eu entrei aqui, eu trabalhava de... ah... 11 e meia às 5. De 11 às 5? Não estou lembrado de que horas até que horas... tem muito tempo. [...] Aqui é meu plantão, aqui não tem "tora” [venda ambulante] não. No lugar onde eu ficava de plantão de colete azul, eu tirava os caras mesmo. Não deixava eles venderem não. [...] Teve uma vez aqui na Tupinambás com Rio de Janeiro que eu cheguei perto do cara: "meu irmão, muito boa tarde, você podia tirar sua barraca aqui porque aqui é meu plantão e aqui você não vai poder vender não." Aí ele pegou e falou assim "meu irmão, vou falar com você um negócio. Você chegou na rua agora. Eu sou ex-presidiário. Eu estou aqui para ganhar o meu.. Eu falei "olha aqui, o que você é, o que você deixou de ser para mim não é problema meu. Aqui é meu plantão. Você não vai sair não?”. “Vou sair não véi, vou sair não!”. Biquei a banca dele! Dei um bicudão 
que voou DVD para tudo quanto é lado! Aí ele pegou e falou assim "Cê é doido, você está mesmo caçando confusão comigo!”. Aí eu falei "pode vir! Eu estou pedindo com educação, na moral, e você não quer sair, aí eu tenho que fazer isso mesmo." Aí na época o Major [um militar reformado, seu supervisor na época] gostou da minha atitude de ter feito isso e falou "nossa, você não pode ficar no plantão não. Você vai trabalhar no Apoio. Nós vamos montar uma outra equipe da Sexta Cia do Apoio, mas vai ser da manhã. Você tem disponibilidade de trabalhar de manhã? Falei "nossa, tenho sim, vamos trabalhar de manhã." Aí comecei a trabalhar no Apoio. Montou uma equipe e me colocou.

Por outro lado, desde o ponto de vista dos auxiliares do plantão, também se confirma a lógica de oposição entre os "perfis". Foram recorrentes as críticas feitas aos agentes do Apoio que são apontados constantemente por não obedecerem aos supostos limites de suas atribuições, por serem, frequentemente, "folgados" e truculentos com os ambulantes.

O relato a seguir foi produzido durante trabalho de campo, quando acompanhava o plantão no centro da cidade. Um dos auxiliares em plantão foi Vagner (33 anos), com quem tive maior proximidade e acabou confessando seu ponto de vista sobre os colegas que fazem as apreensões:

O auxiliar me descreve o seu trabalho como uma atividade que depende muito do que chamou de "técnica", isto é, uma maneira de dizer que existe um comportamento adequado nesse tipo de serviço, "como tudo que se faz", explica. Segundo ele, um aspecto determinante do trabalho é a maneira de realizar a abordagem, que deve ser tranquila e bem medida, quer dizer, o auxiliar deve saber entender "até onde pode ir", e aponta: "até policial sabe a hora que tem que recuar", "se você sabe como evitar [problemas, confusões], por que não evitar né?!” Diz ainda que é comum que alguns ambulantes acatem mais tranquila e rapidamente seu pedido para dispersarem em respeito à forma gentil, "com educação", com que lhes trata.

A fim de fazer um contraste à sua conduta "técnica", conta-me sobre alguns outros auxiliares que, segundo ele, extrapolam o papel como auxiliar de fiscalização. Ele se referia a determinados auxiliares do Apoio (ainda que alguns azuizinhos também tenham esse tipo de atitude), e os denominou como "vibradores", "sangue nos olhos". Conta que não se identifica com estes colegas pois eles excedem o que o serviço e as situações demandam: agem com truculência, ameaçam os ambulantes, tomam as mercadorias (às vezes sem a presença ou a ordem do fiscal), correm atrás de assaltantes, e 
mais, segundo Vagner, pensam o seu território de atuação como sendo "área deles". Em tom crítico, se pergunta: "por que não fazem concurso pra polícia então?". [extrato de caderno de campo]

Em comparação aos "truculentos" agentes de Apoio, Vagner valoriza sua capacidade de comunicação, de abordagem pacífica, sua "técnica”, como diz. Os critérios dessas diferenciações estão no núcleo do que seria a criação de identidades laborais, fruto de uma socialização contínua, vivida e reproduzida por estes grupos e subgrupos de trabalhadores no curso da "construção de si” (Dubar, 2012). Constantemente postos a se comunicarem e a negociarem com os ambulantes para tornar o serviço exequível, partem de vieses distintos sobre a mecânica do controle e para atribuírem sentidos aos papéis que assumem. Por efeito, apresentam diferentes referências do que seria uma conduta adequada para o trabalho, porém também integrado dentro de uma ética da respeitabilidade entre trabalhadores que, na maioria dos casos, trata-se de uma relação entre homens.

Auxiliares de fiscalização e ambulantes tomam ônibus para as periferias, se cruzampelasruas do Centroe dosbairros, cruzam-senosmesmos espaços delazer, reconhecem-se por falarem as mesmas gírias, têm origens sociais semelhantes. Frente a isso, o trabalho de "proximidade" representado pelas abordagens diretas aos ambulantes só se faz possível (e é assim instrumentalizada) devido ao compartilhamento de códigos, valores, experiências de vida entre os atores dos dois grupos, tornando plausível a coexistência da fiscalização e do comércio ambulante. Assim, valida-se o modelo de regulação do comércio ambulante que tem como base a força de trabalho dos auxiliares de fiscalização. Isso se faz mais evidente pela atuação dos plantões, quando há facilitação da negociação das regras, mas também pelas situações de apreensão, por meio da naturalização da violência como parte da experiência de trabalho, tanto de quem apreende, quanto de quem tem as mercadorias apreendidas.

Se, por um lado, as diferenças procedimentais e de conduta entre os dois grupos expõe hierarquias internas; por outro, as referências dessa distinção revelam o que há de transversal enquanto característica desse grupo profissional. Entre uma etapa da mecânica de controle e outra, entre negociações e apreensões, o corpo operacional da fiscalização se divide e aprende a se situar diante dessas representações grupais aparentemente ambíguas.

Apesar de subalternos, os auxiliates são agentes ativos da gestão dos espaços. Tanto no contexto do plantão quanto no Apoio, por meio da prática de trabalho dos auxiliares produz-se dinamicamente os parâmetros de diferenciação entre o tolerável/intolerável, regular/irregular, formal/informal. O 
papel que cumprem para a dinâmica da fiscalização converte-se, portanto, em instrumentos para a legibilidade de públicos-alvo (no sentido de Scott, 1998) e, por fim, participam da produção dos parâmetros de ação estatal na gestão dos espaços públicos.

\section{Considerações finais}

Neste texto, busquei analisar os principais aspectos que circunscrevem o trabalho dos auxiliares de fiscalização, com base em suas principais frentes de atuação. Levo em conta suas especificidades operacionais e de experiência laboral para, finalmente, compreender como são mobilizados como força de trabalho da fiscalização do comércio ambulante. Para isso, atentei-me desde à disponibilidade para os tipos de atividades e seus riscos, o reconhecimento de seus referenciais de conduta e as formas de individualização/responsabilização característicos do nível operacional (e subalterno) da fiscalização. Por meio da maneira com que os auxiliares de fiscalização se compreendem, são compreendidos e se relacionam com os demais, é possível analisar a agência estatal para além do que está anunciado desde um ponto de vista formal.

De forma geral, o trabalho dos auxiliares em ambas frentes funcionam como amortecedores de conflito. $\mathrm{O}$ trabalho nas "pontas" antecipa-se à participação dos fiscais e de outras autoridades. Isto é, a atuação de centenas de funcionários terceirizados e de baixa remuneração diminui a carga de trabalho "de rua" do plantel bastante enxuto de fiscais concursados, escolarizados e bem pagos.

Destaco que esta configuração demonstra a potência gestionária da terceirização. As tensões da rua, quando circunscritas ao rol de atuação de funcionários, mascara as controvérsias políticas por trás da ocupação dos ambulantes nos espaços públicos. Isso quer dizer que a pouca prescrição das funções e o caráter relacional inscritos nas tarefas diárias dos funcionários deste nível operacional ganham positividade pelo ponto de vista de uma administração dos conflitos sociais.

O olhar atento aos elementos que compõem as trajetórias e as dinâmicas interacionais da rua indica a compreensão dos papéis desempenhados por estes sujeitos e, mais amplamente, os modos de governança estruturados pela instrumentalização dessas disposições práticas. O trabalho dos auxiliares da Prefeitura de Belo Horizonte - tanto no plantão, quanto no Apoio - apresenta-se como uma peça fundamental para a conformação do modelo de controle social em questão que, por sua vez, apresenta-se como expressão típica da governabilidade neoliberal. 


\section{Referências}

ARAÚJO FILHO, Tarcísio Perdigão. A construção de um controle negociado: o trabalho dos auxiliares de fiscalização da Prefeitura de Belo Horizonte. Dissertação (Mestrado em Sociologia). CECH - UFSCar, 2016.

. Os toreros em Belo Horizonte: construindo caminhos na contramão das ruas da cidade. CADERNOS CERU (USP), v. 29, 2018, pp. 361-388.

AZAÏS, Christian. A zona cinzenta do assalariamento: os contornos da legalidade. In: AZAÏS, Christian; KESSLER, Gabriel; TELLES, Vera (orgs.). Ilegalismos, cidade e política: perspectivas comparativas. Belo Horizonte, Fino Traço, 2010, pp. 167-198.

BECKER, Howard S. Outsiders: Estudos de sociologia do desvio. Rio de Janeiro, Zahar, 2008. BERGER, Peter; LUCKMANN, Thomas. A construção social da realidade. Rio de Janeiro, Editora Vozes, 1999.

BUREAU, Marie-Christine; GIRAUD, Olivier; CORSANI, Antonella; REY, Frédéric. Les zones grises des relations de travail et d'emploi. Un dictionnaire sociologique. Paris, Teseo Press, 2019.

CABANES, Robert. Qual dialética é possível entre o espaço público e o privado? In: CABANES, Robert; GEORGES, Isabel Pauline Hildegard; RIZEK, Cibele; TELLES, Vera da Silva. Saídas de emergência, São Paulo, Boitempo, 2011, pp. 437-459.

DENARI, Giulianna B. Discussões sobre o trabalho feminino na Polícia Militar do Estado de São Paulo. Revista Novos Rumos Sociológicos, Pelotas, v. 5, n. 8, 2017.

DUBAR, Claude. A construção de si pela atividade de trabalho: a socialização profissional. Cad. Pesqui. São Paulo, v. 42, n. 146, 2012, pp. 351-367.

ENGELS, Friedrich. Origem da família, da propriedade privada e do Estado. São Paulo, Centauro, 2002.

G1. Briga entre camelôs, policial e fiscais termina com detidos em BH. Belo Horizonte, jan. 2019. Disponível em:

<HTTPS://G1.GLOBO.COM/MG/MINAS-GERAIS/NOTICIA/2019/01/24/BRIGAENTRE-CAMELOS-POLICIAL-E-FISCAIS-TERMINA-COM-DETIDOS-EM-BH. GHTML > . Acesso em: 02 dez. 2019.

GEORGES, Isabel Pauline Hildegard; RIZEK, Cibele Saliba; CEBALLOS, Marco. As políticas sociais brasileiras: o que há de novo? Cad. CRH. Salvador, v. 27, n. 72, 2014, pp. 457-461.

GEORGES, Isabel Pauline Hildegard; SANTOS, Yumi. Garcia dos. Care e políticas públicas: o caso das "agentes comunitárias de saúde" e das "agentes de proteção social". In: HIRATA, Helena; GUIMARÃES, Nadya Araújo (orgs.), Cuidado e cuidadoras: as várias faces do trabalho do care. São Paulo, Ed. Atlas, 2012, pp. 166-182.

. Olhares cruzados: relações de cuidado, classe e gênero. Tempo Social, v. 26, n. 1, 2014, pp. 47-60 
As novas políticas sociais brasileiras na saúde e na assistência: Produção local do serviço e relações de gênero. 1 ed. Belo Horizonte, Fino Traço, 2016.

GUIMARÃES, Nadya Araujo; GEORGES, Isabel. A construção social de trajetórias de mando: determinantes de gênero nos percursos ocupacionais. Cad. Pagu. v. 32, jan-jun de 2009, pp. 83-134.

HIRATA, Helena; KERGOAT, Danièle. Novas configurações da divisão sexual do trabalho. Cadernos de Pesquisa, v. 37, n. 132, set/dez. 2007, pp. 595-609.

HOCHSCHILD, Arlie. R. The managed heart: Commercialization of human feeling. Berkeley, CA, University of California Press, 1983.

HUGHES, Everett. C. Men and their work. Free Press, New York, 1958.

LALLEMENT, Michel. Qu'est-ce qu'un travail «normal»?. In : BOURDU, Émilie; LALLEMENT, Michel; VELTZ, Pierre; WEIL, Thierry (Orgs.) Le Travail en Mouvement, Paris, 2019.

LIMA, Jacob Carlos; COCKELL, Fernanda F. As novas institucionalidades do trabalho no setor público: os agentes comunitários de saúde. Trabalho, educação e saúde[online], v. 6, n. 3, 2008, pp. 481-502.

LIMA, Jacob Carlos; MOURA, Maria do Carmo. Trabalho atípico e capital social: os Agentes Comunitários de Saúde na Paraíba. Sociedade e estado, v. 20, n. 1, 2005, pp. 103-133.

LIPSKY, Michael. Street-level Bureaucracy. Dilemmas of the individual in public services. Russell Sage Foundation, New York, 1980.

LOPES, Valquiria. Fiscais da PBH que lidam com ambulantes revelam clima de insegurança e medo nas ruas. Estado de Minas, Belo Horizonte, mar. 2015. Disponível em: $<$ https://www.em.com.br/app/noticia/gerais/2015/03/26/interna_gerais,63140o/ fiscais-que-lidam-com-ambulantes-revelam-clima-de-inseguranca-e-medo-n. shtml>. Acesso em: 02 dez. 2019.

MISSE, Michel. O Rio como um bazar. A conversão da ilegalidade em mercadoria política. Insight Inteligência (Rio de Janeiro), Rio de Janeiro, v. 5, n. 18, 2002, pp. 68-79. MOLINIER, Pascale. Ética e trabalho do care. In: HIRATA, Helena; GUIMARÃES, Nadya. (Orgs.). Cuidado e cuidadoras. As várias faces do trabalho do care. São Paulo, Atlas, 2012, pp. 29-43.

MUNIZ, Jacqueline. Ser policial é, sobretudo, uma razão de ser: cultura e cotidiano da Polícia Militar do Estado do Rio de Janeiro. Rio de Janeiro, IUPERJ, 1999.

OLIVEIRA, Cinthya. Camelôs e ambulantes reclamam de violência de guardas durante fiscalizações. Belo Horizonte, nov. 2017. Disponível em: <https://www. hojeemdia.com.br/horizontes/camel\% $\mathrm{C}_{3} \% \mathrm{~B}_{4}$ s-e-ambulantes-reclamam-deviol\% $\mathrm{C}_{3} \% \mathrm{AAncia}$-de-guardas-durante-fiscaliza\% $\mathrm{C}_{3} \% \mathrm{~A} 7 \% \mathrm{C}_{3} \% \mathrm{~B}_{5}$ es-1.572192>. Acesso em: 02 dez. 2019. 
PONCIONI, Paula. O modelo policial profissional e a formação profissional do futuro policial nas academias de policiamento do estado do Rio de janeiro. In: Sociedade e Estado, Brasília, v. 20, n. 3, 2005, pp. 585-610.

ROSA, Alexandre Reis. (O) Braço forte,(A) Mão amiga: um estudo sobre dominação masculina e violência simbólica em uma organização militar. Dissertação (Mestrado em Administração), UFLA, 2007.

SCOTT, James. Seeing Like a State: How Certain Schemes to Improve the Human Condition Have Failed. New Haven, Conn.: Yale University Press, 1998.

_. Exploração normal, resistência normal. Revista Brasileira de Ciência Política, Brasília, n. 5, 2011, pp. 217-243.

SOARES, Angelo. As emoções do care. In: HIRATA, Helena; GUIMARÃES, Nadya Araujo (org.). Cuidado e cuidadoras. As várias faces do trabalho do care. São Paulo, Atlas, 2012, pp. 44-59.

Como segredos: as lágrimas no trabalho. In: LIMA, Jacob Carlos. (org.) Outras sociologias do trabalho: flexibilidades, emoções e mobilidades. São Carlos, EdUFSCar, 2013, pp. 161-182.

STORANI, Paulo. Vitória Sobre A morte: a glória prometida. O "rito de passagem" na construção da identidade das Operações Especiais do BOPE/PMERJ. Dissertação (Mestrado em Antropologia). UFF, Niterói, 2008.

TELLES, Vera da Silva. Trajetórias urbanas: fios de uma descrição da cidade. In: TELLES, Vera da Silva; CABANES, Robert. (org.), Nas tramas da cidade: trajetórias urbanas e seus territórios. São Paulo, Editora Humanitas, 2006.

TERSSAC, Gilbert de. Autonomie et travail. In: Dictionnaire du travail, PUF, 2012, pp. 47-53. THOMAS, William Isaac; THOMAS, Dorothy. The Child in America: Behavior Problems and Programs. New York, Knopf, 1928.

Recebido em: 10/06/2019

Aprovado em: 06/12/2019

\section{Como citar este artigo:}

ARAÚJO FILHO, Tarcísio Perdigão. A terceirização do controle: uma análise sobre a fiscalização do comércio ambulante, entre trabalho e gênero. Contemporânea Revista de Sociologia da UFSCar, v. 9, n. 3, set.- dez. 2019, pp. 847-872. 